\title{
Prerequisites of Personal Health Record for Chronic Kidney Disease: A Scoping Review and Evaluation of the Content Validity
}

\author{
Fatemeh SALEHI ${ }^{\mathrm{a}}$, Peivand BASTANI ${ }^{\mathrm{a}}$, Leila AHMADIAN ${ }^{\mathrm{b}}$, Katayoon SAMADI ${ }^{\mathrm{c}}$, \\ Azita YAZDANI ${ }^{\mathrm{a}}$, Roxana SHARIFIAN ${ }^{\mathrm{a}}$ \\ ${ }^{\mathrm{a}}$ Health Human Resources Research Center, School of Management \& Information \\ Sciences, Shiraz University of Medical Sciences, Shiraz, Iran \\ ${ }^{\mathrm{b}}$ Department of Health Information Sciences, Faculty of Management and Medical \\ Information Sciences, Kerman University of Medical Sciences, Kerman, Iran \\ ${ }^{\mathrm{c} K i d n e y ~ T r a n s p l a n t a t i o n}$ Complication Research Center, Mashhad University of \\ Medical Sciences, Mashhad, Iran
}

\begin{abstract}
Background: It is obvious that the Personal Health Record (PHR) is a major cornerstone for "improving the self-management of patient". However, lack of an effective and comprehensive personal health record system prohibits the widespread use of PHRs. The aim of this study was to identify the core data sets and required functionalities for designing a PHRs for chronic kidney disease (CKD) management and assess their validity. Methods: It was a study including two phases. In the initial phase, a scoping review was conducted with the aim of determination the core data sets and required functionalities for designing PHRs. Then in the second phase, the validity of data items and functionalities was determined by 25 multidisciplinary experts. Results: 22 studies were eligible after screening 1335 titles and abstracts and reviewing 88 full texts. We determined 20 core data set and 8 required functionalities of PHRs. From the perspective of experts, 'health maintenance' and 'advance directives' were most often marked as useful but not essential, while 'test and examination', 'medication list' and 'diagnosis and comorbid conditions" were predominantly considered as essential by all experts ( $\mathrm{n}=$ $25,100 \%$ ). Conclusion: This research is a step that we have taken to identify prerequisites that could be used for the design, development, and implementation of an effective and comprehensive electronic personal health record.
\end{abstract}

Keywords. Chronic Kidney Disease, Personal Health Record, PHR, CKD, Core data sets

\section{Introduction}

Significant social and economic burdens of chronic diseases have led to a shift in the health policy, involving a focus on health promotion, chronic disease prevention, and self-management [1]. Chronic kidney disease (CKD) is a major public health concern [2-

${ }^{1}$ Corresponding Author: Roxana Sharifian, Associate Professor, School of Management \& Information Sciences, Shiraz University of Medical Sciences, Shiraz, Iran. E-mail: sharifianr@sums.ac.ir 
4]. More than 70 million individuals worldwide have CKD, and according to estimates, the prevalence will further increase as will the already enormous impact CKD has on health system resources related to its care [5,6]. Health information technologies (ITs) have the potential to significantly increase the engagement of patients by using personal health records (PHRs) to electronically connect them to their health information and clinical team and continuity of care [7]. PHR is a tool that has the potential to change and possibly to improve patient-provider relationship and enable the healthcare system to evolve a more personalized medical model and promising results to address some of these challenges [8-10]. Unfortunately, designing and developing programs that improve patient care and obtaining complete and high-quality data in nephrology have remained a challenge [11]. The literature does not yet adequately describe the potential functions and prerequisites of PHRs design [12-15]. So, the objectives of these study were to derive core data sets and functionalities specifically for PHRs for patients diagnosed with CKD and determine the validity of these core data sets and functionalities.

\section{Method}

This review was guided by Arksey and O'Malley's 6-stage scoping review framework [16]. We searched for relevant articles written in English between 1990 and Jan 2021 using PubMed, Science Direct, Web of Science and Embase databases, and the related websites such as guideline.gov, IEEE, and WHO. A combination of keywords and Medical Subject Headings (MeSH) were used as follows: group A included PHR-related terms and group B included terms related to "kidney failure chronic." We considered all the full text papers with quantitative, qualitative, or mix method designs and full reports that studied PHRs and determined the data elements and functionalities of chronic kidney disease PHR. However, the papers in the formats of letter to editor, short communication and commentary, and articles in non-English language or those with English abstracts published in languages other than English were excluded. Additionally, if the study was about a personal electronic record but had not the state data items and functionalities, it was excluded from the study. After searching the studies from all databases and eliminating duplicates, the studies were independently reviewed and screened by two members of the research team (FS and RSH) in three phases by title, abstract, and then the full text of the articles. Studies meeting the inclusion criteria were critically reviewed using Arksey and O'Malley's summative analysis method [16] according to the frequency of the items in the included studies. To validate the core data sets and functionalities, we formed an expert panel. The panel consisted of 25 multidisciplinary experts that were recruited base purposive sampling. In this way, the experts are requested to specify whether the core data sets and functionalities is necessary for designing a PHR for CKD or not via email. To this end, they are requested to score each item from 1 to 3 with a three-degree range of "not necessary, useful but not essential, essential" respectively. The formula of content validity ratio is $C V R=(\mathrm{Ne}-\mathrm{N} / 2) /(\mathrm{N} / 2)$, in which the $\mathrm{Ne}$ is the number of panelists indicating "essential" and $\mathrm{N}$ is the total number of panelists. The numeric value of content validity ratio is determined by Lawshe table [17]. Ethical approval was received from the Shiraz University of Medical Sciences by Dr Abbas Rezaeianzadeh, (Ethical number: IR.SUMS.REC.AC.IR.1399.1310). 


\section{Results}

In total, 1335 studies were selected after searching the databases. After removing the duplicates, screening, and applying inclusion and exclusion criteria, 88 studies were eligible for further full-text review. Thereafter, 16 articles, 4 reports, and 2 guidelines were selected for the final analysis.

Most studies were journal article $(n=16,76 \%)$, published in the USA $(n=10,45 \%)$, and published between 2012 and $2018(\mathrm{n}=15,71 \%)$ (Table1).

Table1. Description of included study

\begin{tabular}{|c|c|c|c|}
\hline First author name \& [Ref] & Resource type & Publication Date & Country/Institution \\
\hline Venuthurupalli ${ }^{[18]}$ & Article (Cross sectional) & 2017 & Australia \\
\hline Nakashima ${ }^{[10]}$ & Article (Cross sectional) & 2019 & Japan \\
\hline Drawz $^{[20}$ & Article (RCT) & 2012 & USA \\
\hline Mendu [21] & Article (Cross sectional) & 2019 & USA \\
\hline Drawz $^{[22]}$ & Article (Review) & 2015 & USA \\
\hline Bruland ${ }^{[25]}$ & Article (Case report) & 2016 & Germany \\
\hline Do ${ }^{[26]}$ & Article (project report) & 2011 & USA \\
\hline Archer ${ }^{[9]}$ & Article (Review) & 2011 & Canada \\
\hline Kaelber ${ }^{[11]}$ & Article (Cross sectional) & 2008 & USA \\
\hline Gearon $^{[27]}$ & Report & 2007 & California \\
\hline Tang ${ }^{[32]}$ & Article & 2006 & USA \\
\hline Dickinson ${ }^{[33]}$ & Guideline & 2014 & USA \\
\hline Unknown $^{[34]}$ & Report & 2012 & European \\
\hline Katehakis $^{[35]}$ & Article (Review) & 2017 & Greece \\
\hline
\end{tabular}

Table2. Core data sets for designing PHRs for chronic kidney disease based on evidence and expert panel.

\begin{tabular}{|c|c|c|c|c|c|c|}
\hline \multirow[t]{2}{*}{ Core Data Sets } & \multirow{2}{*}{$\begin{array}{c}\text { Frequency } \\
(\%)\end{array}$} & \multicolumn{3}{|c|}{ Expert Panel } & \multirow[t]{2}{*}{ CVR* } & \multirow[t]{2}{*}{ Interpretation } \\
\hline & & Essential & $\begin{array}{l}\text { Useful not } \\
\text { essential }\end{array}$ & Unnecessary & & \\
\hline Problem list & $7(31.81 \%)$ & $24(96 \%)$ & $1(4 \%)$ & 0 & 0.92 & Remained \\
\hline Diagnosis/comorbid conditions & $9(40.90 \%)$ & $25(100 \%)$ & 0 & 0 & 1 & Remained \\
\hline Medications list & $12(54.54 \%)$ & $25(100 \%)$ & 0 & 0 & 1 & Remained \\
\hline Health maintenance & $1(4.54 \%)$ & $16(64 \%)$ & $7(28 \%)$ & $2(8 \%)$ & 0.28 & Eliminated \\
\hline Disease characteristic & $2(9.00 \%)$ & $24(96 \%)$ & $1(4 \%)$ & 0 & 0.92 & Remained \\
\hline Advance directives & $2(9.00 \%)$ & $17(\% 68)$ & $2(8 \%)$ & $6(22 \%)$ & 0.36 & Eliminated \\
\hline Physical examination & $2(9.00 \%)$ & $22(88 \%)$ & $2(8 \%)$ & $1(\% 4)$ & 0.76 & Remained \\
\hline Wellness management & $3(13.62 \%)$ & $22(88 \%)$ & $3(12 \%)$ & 0 & 0.76 & Remained \\
\hline Care plan & $2(9.00 \%)$ & $23(92 \%)$ & $1(\% 4)$ & $1(\% 4)$ & 0.84 & Remained \\
\hline Health patterns & $7(31.81 \%)$ & $20(74 \%)$ & $4(14 \%)$ & $1(\% 4)$ & 0.60 & Remained \\
\hline Test and examination & $17(77.27 \%)$ & $27(100 \%)$ & 0 & 0 & 1 & Remained \\
\hline Functional status & $2(9.00 \%)$ & $21(84 \%)$ & $3(12 \%)$ & $1(\% 4)$ & 0.68 & Remained \\
\hline
\end{tabular}

Finally, 124 data items were identified from the literature that classified in 20 core data set. "Test and examination" was the most common core data set examined $(n=17)$ in the included studies. Other common core data item examined included medication list $(n=12)$, "diagnosis and comorbid conditions", "preventive care \& immunization" and "demographics data" (n=9). About data sets, 'health maintenance', and 'advance directives' were most often marked as useful but not essential or unnecessary, while 'test 
and examination', 'medication list' and 'diagnosis and comorbid conditions", were predominantly considered as essential by all experts $(n=25,100 \%)$ (Table2).

Table 3. Required functionality in designing PHRs for CKD based on evidence and expert panel.

\begin{tabular}{|c|c|c|c|c|c|c|}
\hline \multirow[b]{2}{*}{$\begin{array}{l}\text { Required } \\
\text { functionality }\end{array}$} & \multirow{2}{*}{ Sub items } & \multirow[b]{2}{*}{ Frequency } & \multicolumn{3}{|c|}{ Expert plan } & \multirow{2}{*}{ CVR* } \\
\hline & & & Essential & $\begin{array}{l}\text { Useful, not } \\
\text { essential }\end{array}$ & Unnecessary & \\
\hline Historical data & Manage historical clinical data & $4(18.18 \%)$ & $24(96 \%)$ & $1(4 \%)$ & 0 & 0.92 \\
\hline \multirow{5}{*}{$\begin{array}{l}\text { Management } \\
\text { observations }\end{array}$} & Manage clinical observations & $3(13.62 \%)$ & $18(72 \%)$ & $7(28 \%)$ & 0 & 0.44 \\
\hline & Manage test results & $3(13.62 \%)$ & $25(100 \%)$ & 0 & 0 & 1 \\
\hline & Manage provider care plans & $2(9.00 \%)$ & $23(92 \%)$ & $1(4 \%)$ & $1(4 \%)$ & 0.84 \\
\hline & Manage health calendar & $2(9.00 \%)$ & $23(92 \%)$ & $1(4 \%)$ & $1(4 \%)$ & 0.84 \\
\hline & Manage medication & $9(40.90 \%)$ & $25(100 \%)$ & 0 & 0 & 1 \\
\hline \multirow{4}{*}{$\begin{array}{l}\text { Management of } \\
\text { decision support }\end{array}$} & Manage drug interaction checking & $3(13.62 \%)$ & $18(72 \%)$ & $7(28 \%)$ & 0 & 0.44 \\
\hline & Manage guidelines and protocols & $2(9.00 \%)$ & $21(84 \%)$ & $2(8 \%)$ & $2(8 \%)$ & 0.68 \\
\hline & Manage health alerts & $3(13.62 \%)$ & $23(92 \%)$ & $2(8 \%)$ & 0 & 0.84 \\
\hline & Manage health reminders & $6(27.27 \%)$ & $23(92 \%)$ & 0 & $2(8 \%)$ & 0.84 \\
\hline \multirow{6}{*}{$\begin{array}{l}\text { Management of } \\
\text { patient support }\end{array}$} & Manage custom patient education & $6(27.27 \%)$ & $23(92 \%)$ & $2(8 \%)$ & 0 & 0.84 \\
\hline & Manage family education & $2(9.00 \%)$ & $23(92 \%)$ & $2(8 \%)$ & 0 & 0.84 \\
\hline & Manage data input errors & $3(13.62 \%)$ & $24(96 \%)$ & $1(4 \%)$ & 0 & 0.92 \\
\hline & Manage trading patterns & $2(9.00 \%)$ & $21(84 \%)$ & $2(8 \%)$ & $2(8 \%)$ & 0.68 \\
\hline & Manage shared patient experience & $4(18.18 \%)$ & $15(60 \%)$ & $1(4 \%)$ & $9(36 \%)$ & 0.20 \\
\hline & Manage results notification & $2(9.00 \%)$ & $23(92 \%)$ & $2(8 \%)$ & 0 & 0.84 \\
\hline \multirow{9}{*}{$\begin{array}{l}\text { Management of } \\
\text { security }\end{array}$} & Manage secure the access to PHR & $2(9.00 \%)$ & $24(96 \%)$ & $1(4 \%)$ & 0 & 0.92 \\
\hline & Manage entity authentication & $2(9.00 \%)$ & $24(96 \%)$ & $1(4 \%)$ & 0 & 0.92 \\
\hline & Manage entity authorization & $2(9.00 \%)$ & $24(96 \%)$ & $1(4 \%)$ & 0 & 0.92 \\
\hline & Manage secure data exchange & $2(9.00 \%)$ & $24(96 \%)$ & $1(4 \%)$ & 0 & 0.92 \\
\hline & Manage patient privacy & $4(18.18 \%)$ & $24(96 \%)$ & $1(4 \%)$ & 0 & 0.92 \\
\hline & Manage secure messaging & $3(13.62 \%)$ & $24(96 \%)$ & $1(4 \%)$ & 0 & 0.92 \\
\hline & Manage consents and authorizations & $2(9.00 \%)$ & $23(92 \%)$ & $1(4 \%)$ & $1(4 \%)$ & 0.84 \\
\hline & Manage data masking for sensitive & $2(9.00 \%)$ & $22(88 \%)$ & $3(12 \%)$ & 0 & 0.76 \\
\hline & Manage a registry of actors & $2(9.00 \%)$ & $24(96 \%)$ & $1(4 \%)$ & 0 & 0.92 \\
\hline \multirow{10}{*}{$\begin{array}{l}\text { Management of } \\
\text { administrative } \\
\text { issues }\end{array}$} & Manage demographics information & $3(13.62 \%)$ & $24(96 \%)$ & $1(4 \%)$ & 0 & 0.92 \\
\hline & Management scheduling & $7(31.81 \%)$ & $24(96 \%)$ & $1(4 \%)$ & 0 & 0.92 \\
\hline & Manage advance care directives & $2(9.00 \%)$ & $17(\% 68)$ & $2(8 \%)$ & $6(24 \%)$ & 0.36 \\
\hline & Manage insurance eligibility & $3(13.62 \%)$ & $21(84 \%)$ & $1(4 \%)$ & $3(12 \%)$ & 0.68 \\
\hline & Manage clinical trial recruitment & $2(9.00 \%)$ & $22(88 \%)$ & 0 & $3(12 \%)$ & 0.76 \\
\hline & Manage multiple views of data & $2(9.00 \%)$ & $22(88 \%)$ & $3(11 \%)$ & 0 & 0.76 \\
\hline & Manage donor information & $2(9.00 \%)$ & $16(64 \%)$ & $5(20 \%)$ & $4(16 \%)$ & 0.28 \\
\hline & Manage access to public health & $2(9.00 \%)$ & $20(80 \%)$ & $4(16 \%)$ & $1(4 \%)$ & 0.60 \\
\hline & Manage clinical research & $2(9.00 \%)$ & $24(96 \%)$ & 0 & $1(4 \%)$ & 0.92 \\
\hline & Manage clinical dashboard & $3(13.62 \%)$ & $22(88 \%)$ & $2(8 \%)$ & $1(4 \%)$ & 0.76 \\
\hline \multirow{4}{*}{$\begin{array}{l}\text { Management of } \\
\text { electronic } \\
\text { communication }\end{array}$} & Manage team coordination & $2(9.00 \%)$ & $23(92 \%)$ & $2(\% 8)$ & 0 & 0.84 \\
\hline & Manage of communication & $9(40.90 \%)$ & $25(100 \%)$ & 0 & 0 & 1 \\
\hline & Manage contact information & $5(22.72 \%)$ & $23(92 \%)$ & $2(\% 8)$ & 0 & 0.84 \\
\hline & Manage referral authorizations & $3(13.62 \%)$ & $16(64 \%)$ & $6(24 \%)$ & $3(12 \%)$ & 0.28 \\
\hline \multirow{2}{*}{$\begin{array}{l}\text { Management } \\
\text { health } \\
\text { monitoring }\end{array}$} & Manage Home monitoring & $8(36.36 \%)$ & $23(92 \%)$ & $2(\% 8)$ & 0 & 0.84 \\
\hline & $\begin{array}{l}\text { Manage wellness, preventive, life } \\
\text { style }\end{array}$ & $4(18.18 \%)$ & $23(\% 92)$ & $1(\% 4)$ & $1(\% 4)$ & 0.84 \\
\hline
\end{tabular}

NOTE: ${ }^{*}$ CVR or Content Validity Ratio $=\left(\mathrm{N}_{\mathrm{e}}-\mathrm{N} / 2\right) /(\mathrm{N} / 2)$ with 25 persons at the expert panel $(\mathrm{N}=25)$, the items with the CVR bigger than 0.37 remained at the instrument and the rest eliminated.

In terms of required functionalities, 'manage of communication, 'manage medications' and 'manage test and examination' were considered as essential by all experts $(n=25,100 \%)$. Management of clinical research information and clinical trial recruitment were other functionalities recommended by experts. According to result of expert panel, 2 items out of core data sets items (health maintenance \& advance directives) and 4 items out of functionalities (manage shared patient experience, manage advance directives, manage donor information $\&$ manage referral authorizations) were eliminated (Table 2\&3). 


\section{Discussion}

Based on the results of our study, 20 core data sets were determined. Core data items proposed by this study covered all 11 data components essential for PHRs that were prepared by consensus set of standards of CCD, CCA, CCR, AHIMA, AMIA, DICOM, immunizations, medications, allergies, family history, lab/test results, and procedures/surgeries $[28,32]$. The corresponding PHRs for CKD, 'advanced directives', was checked as unnecessary in most of responses by experts. Considering that advanced directives are not popular in Iran, the number was expected. These findings contrast with other countries which "advanced directives" is very important and, indeed, the legal right of the patient $[28,36]$. These differ may be due to cultural differences between Iran and other countries might influence the choice of key data sets/functionalities. Essential functionalities that recommended by experts in designing PHRs for CKD were consistent with the results of other on literature $[6,10,11,18,19,26,28,29]$. An innovative function under strong focused of experts is the "custom patient education". Health care delivery moves towards a more consumer focused, personalized care, patients and individuals' roles grow, and many potential advantages of the PHR have been portrayed [37].

\section{Conclusions}

We propose pre-requisites of personal health record consisting of 20 core data sets and 8 main functionalities for CKD patient. These pre-requisites could be used for designing and implementing effective and comprehensive PHRs for chronic kidney disease management.

\section{Acknowledgment}

This article is adopted from a $\mathrm{PhD}$ dissertation approved by Shiraz University of medical sciences, Shiraz, Iran

\section{References}

[1] Jordan JE, Osborne RH. Chronic disease self-management education programs: challenges ahead. Medical Journal of Australia 2007; 186: 84 - 87.

[2] Zhang L, Wang F, Wang L, Wang W, Liu B, Liu J, et al, Prevalence of chronic kidney disease in China: a cross-sectional survey. Lancet 2012;379:815-822.

[3] GBD 2013 Mortality and Causes of Death Collaborators: a systematic analysis for the global burden of disease study. Lancet 2015;385:117-171.

[4] Braun L, Sood V, Hogue S, Lieberman B, Copley-Merriman C, High burden and unmet patient needs in chronic kidney disease. Int J Nephrol Renovasc Dis 2012;5:151-163.

[5] Go AS, Chertow GM, Fan D, McCulloch CE, Hsu CY, Chronic kidney disease and the risks of death, cardiovascular events, and hospitalization. N Engl J Med 2004;351:1296-1305.

[6] Mendu ML, Schneider LI, Aizer AA, Singh K, Leaf DE, Lee TH, Waikar SS, Implementation of a CKD checklist for primary care providers. Clin J Am Soc Nephrol 2014;9:1526-1535.

[7] Wells, S et al. Personal health records for patients with chronic disease: a major opportunity. Applied clinical informatics 2014;5:416-29.

[8] Roehrs A, da Costa CA, da Rosa Righi R, de Oliveira KSF. Personal Health Records: A Systematic Literature Review. J Med Internet Res 2017;19. 
[9] Archer N, Fevrier-Thomas U, Lokker C, McKibbon KA, Straus SE (2011) Personal health records: a scoping review. J Am Med Inform Assoc 2011;18:515-522.

[10] Nakashima $\mathrm{N}$ et al. Recommended configuration for personal health records by standardized data item sets for diabetes mellitus and associated chronic diseases. J Diabetes Investig 2019;10:868-875.

[11] Kaelber DC, Jha AK, Johnston D, et al. A research agenda for personal health records (PHRs). J Am Med Inform Assoc 2008;15:729.

[12] Public Health England -Trust Development Authority. NHS England Care Quality Commission Health Education England Monitor NHS England Care Quality Commission Health Education England Monitor (2014).

[13] National Information Board. Personalised Health and Care 2020: Using Data and Technology to Transform Outcomes for Patients and Citizens.

[14] Ford EW, Hesse BW, Huerta TR, Personal Health Record Use in the United States: Forecasting Future Adoption Levels. J Med Internet Res 2016;18:e73.

[15] Tang, Paul C et al. Personal health records: definitions, benefits, and strategies for overcoming barriers to adoption. Journal of the American Medical Informatics Association 2006;13:121-6.

[16] Sea1-Arksey H, O'Malley L. Scoping studies: towards a methodological framework. Int J Soc Res Methodol 2005;8:19-32.

[17] Lawshe CH. A quantitative approach to content validity. Personnel psychology 1975;28:563-75.

[18] Venuthurupalli SK, Hoy WE, Healy HG, Cameron A, Fassett RG, CKD.QLD: establishment of a chronic kidney disease [CKD] registry in LQueensland, Australia. BMC Nephrol 2017;18:189.

[19] Navaneethan SD, Jolly SE, Sharp J, et al. Electronic health records: a new tool to combat chronic kidney disease? Clin Nephrol 2013;79(3):175-183.

[20] Drawz et al. Impact of a chronic kidney disease registry and provider education on guideline adherence - a cluster randomized controlled trial. BMC Medical Informatics and Decision Making 2012;12:62.

[21] Mendu ML, Ahmed S, Maron JK, Rao SK, et al. Development of an electronic health record-based chronic kidney disease registry to promote population health management. BMC Nephrol 2019;20:72.

[22] Drawz PE, Archdeacon P, McDonald CJ, et al. CKD as a Model for Improving Chronic Disease Care through Electronic Health Records, Clin J Am Soc Nephrol 2015;10:1488-1499.

[23] Khan IA. Personalized Electronic Health Record System for Monitoring Patients with Chronic Disease. Systems and Information Engineering Design Symposium (SIEDS) (Conference paper) IEEE (2013).

[24] Venuthurupalli SK, Rolfe A, Fanning J, Cameron A, Hoy WE, NHMRC CKD.CRE and the CKD.QLD Collaborative. Chronic Kidney Disease, Queensland (CKD.QLD) Registry: Management of CKD with Telenephrology. Kidney Int Rep 2018;3:1336-1343.

[25] Bruland et al. Common data elements for secondary use of electronic health record data for clinical trial execution and serious adverse event reporting. BMC Medical Research Methodology 2016;16:159.

[26] Do NV, Barnhill R, Heermann-Do KA, Salzman KL, Gimbel RW. The military health system's personal health record pilot with Microsoft HealthVault and Google Health. J Am Med Inform Assoc 2011;18:118-124.

[27] Georghen C, et al. Perspective of future of personal health record. California health care foundation (2007).

[28] Tran BQ, Gonzales P. Standards and Guidelines for Personal Health Records in the United States: Finding Consensus in a Rapidly Evolving and Divided Environment. J Health Med Information (2012).

[29] Evaluation of Personal Health Records Pilots for Fee-for-Service Medicare Enrollees from South Carolina. NORC at the University of Chicago (2010).

[30] The value of Value of Personal Health Records, a Joint Position Statement for Consumers of Health Care (2007) AHIMA/AMIA https://library.ahima.org/doc?oid=100380. Accessed 01 June 2021

[31] Roehrs A, da Costa CA, Righi RD, de Oliveira KS (2017) Personal Health Records: A Systematic Literature Review. J Med Internet Res 2017;19:e13.

[32] Tang PC, Ash JS, Bates DW, Overhage JM, Sands DZ. Personal health records: definitions, benefits, and strategies for overcoming barriers to adoption. J Am Med Inform Assoc 2006;13:121-126.

[33] Personal Health Record System Functional Model (PHR-S FM), R1. HL7/ANSI (2014)

[34] PHR Design and Architecture. Project \# FP7-ICT-StrokeBack-288692 (2012) Version 1.

[35] Katehakis DG, Kondylakis H, Koumakis L, Kouroubali A, and Marias K, Integrated Care Solutions for the Citizen: Personal Health Record Functional Models to Support Interoperability. EJBI 2017;13.

[36] Fong KC, Chiong W. Understanding Advance Directives as a Component of Advance Care Planning. The American Journal of Bioethics 2020;20:67-69.

[37] Lee M, Delaney C, Moorhead S. Building a personal health record from a nursing perspective. Int J Med Inform. 2007;76:S308-S316. 